\title{
MODEL RASCH: ANALISIS SKALA RESILIENSI CONNOR-DAVIDSON VERSI BAHASA INDONESIA
}

\author{
Amien Wahyudi ${ }^{1}$,Muhammad Junaedi Mahyuddin ${ }^{2}$,Andi Wahyu Irawan ${ }^{3}$, Dodi Priyatmo Silondae ${ }^{4}, M_{a r d i}$ \\ Lestari $^{5}$,Fabianus Hadiman Bosco ${ }^{6}$,Shopyan Jepri Kurniawan ${ }^{7}$ \\ Universitas Ahmad Dahlan ${ }^{1,7}$, Universitas Muhammadiyah Enrekang $^{2}$, Universitas Mulawarman $^{3}$, Universitas Halu $^{2}$ \\ $\mathrm{Oleo}^{4}$, Universitas Tadulako $^{5}$, STKIP Santo Paulus Ruteng 6 \\ Corresponding Autor:tommuanemandar@gmail.com
}

\begin{tabular}{|c|c|}
\hline Article Info & \\
\hline & \\
\hline $\begin{array}{l}\text { Available online } \\
15.06 .2020\end{array}$ & $\begin{array}{l}\text { Sebuah skala yang berasal dari luar negeri saat akan digunakan di Indonesia membutuhkan adaptasi } \\
\text { agar sesuai dengan karakteristik responden di Indonesia.Studi ini dilakukan untuk mengadaptasi } \\
\text { Skala Connor-Davidson (CD-RISC) ke dalam bahasa Indonesia. Responden penelitian ini sebanyak } \\
303 \text { mahasiswa yang berasal dari Universitas yang berada di Propinsi Yogyakarta,Sulawesi } \\
\text { Tenggara,Sulawesi Barat,Kalimantan Timur,Sulawesi Utara,Sulawesi Tengah dan Nusa Tenggara } \\
\text { Timur. Hasil penelitian menunjukan Alfa Cronbach sebesar } 0.90 \text {.Nilai reliebelitas aitem sebesar } \\
0.92 \text { dan nilai reliabelitas person sebesar 0.88.Berdasarkan perhitungan model rasch, skala adaptasi } \\
\text { ini memiliki syarat yang memadai untuk digunakan sebagai intrumen penelitian atau pengukuran. } \\
\text { Kata Kunci.Resiliensi,adaptasi dan model rasch }\end{array}$ \\
\hline
\end{tabular}

\section{Abstract}

The scale used from abroad when it will be used in Indonesia needs to be adjusted to suit the characteristics of respondents in Indonesia. This study was conducted to adapt the ConnorDavidson Scale (CD-RISC) into Indonesian. The number of respondents in this study were 303 students from the Universities of Yogyakarta, Southeast Sulawesi, West Sulawesi, East Kalimantan, North Sulawesi, Central Sulawesi and East Nusa Tenggara. The results showed high results on the Cronbach's Alfa value of 0.90. The item reliability value was 0.92 and the reliability value of people was 0.88. Based on the Rasch calculation model, this adaptation scale provides the appropriate needs to be used as research or measurement instruments.

Keywords: Resilience, adaptation and rasch model

\section{PENDAHULUAN}

Resiliensi dipandang sebagai bagian penting bagi perkembangan psikologis individu. Resiliensi didefinisikan sebagai kemampuan lentur individu saat berhadapan dengan satu atau lebih stresor dalam kehidupannya.(Amir \& Kant, 2018; Apneseth et al., 2018; Southwick et al., 2016; Woodgate, 1999). Resiliensi tidak terjadi dengan sendirinya tetapi melalui proses panjang dalam rentang kehidupan individu (Becvar, 2012; Feder et al., 2019).Banyak faktor yang mendukung perkembangan resiliensi individu diantaranya adalah penilaian positif individu,dukungan keluarga,dukungan pasangan hidup,lingkungan, budaya dan pendidikan (Cohen et al., 2019; GarcíaLeón et al., 2019; Hoorelbeke et al., 2019).

Faktor protektif dipandang sebagai faktor yang mendukung perkembangan resiliensi indvidu. Selain faktor protektif, faktor lainnya adalah faktor resiko yang menjadi stresor dalam kehidupan.Diantara faktor resiko yang bisa terjadi pada individu dan memberikan pengaruh terhadap resiliensi adalah bencana alam,pekerjaan yang tidak menentu, tekanan ekonomi,perceraian keluarga 
dan kerusuhan sosial dan pendemi virus (Ensor et al., 2018; Manyena et al., 2019; Sciences et al., 2019). Para ahli telah memberikan pandangan terhadap aspek aspek yang ada di dalam resiliensi.Aspek-aspek tersebut adalah ketekunan, kemandirian, keseimbangan, kebermaknaan dan keunikan diri sendiri, regulasi diri, pengendalian impuls, optimisme, kemampuan menganalisis, empathi, evaluasi diri dan pencapaian (Turk \& Wolfe, 2019; Wagnild, 2009).

Hingga saat ini banyak skala yang telah dikembangkan untuk mengetahui resiliensi individu. Salah satu skala yang banyak digunakan diantaranya adalah skala Resiliensi Connor-Davidson(CDRISC).Skala CD-RISC melihat resiliensi dalam beberapa aspek yaitu kompetensi personal, keyakinan terhadap insting,penerimaan positif,kontrol diri dan spritualitas (Guzmán et al., 2019; Kuiper et al., 2019; Papini et al., 2020). Beberapa penelitian telah mencoba untuk menghitung kebermanfaatan intrumen ini dengan mengambil beberapa setting lokasi diantaranya di negara Singapura dan Spanyol (Gras Pérez et al., 2019; Kwan et al., 2019).Studi lainnya menggunakan skala ini untuk melihat hubungan resiliensi dengan harga diri,regulasi diri,efikasi diri dan kecerdasan emosi (Resnick, 2018; Turk \& Wolfe, 2019; Zhang et al., 2020).

Proses adaptasi sebuah skala merupakan usaha ilmiah yag dilakukan untuk mengetahui apakah intrumen yang diadaptasi tersebut sesuai dengan kondisi budaya dan karateristik masyarakat tempat intrumen tersebut diadaptasi (Stapelfeldt et al., 2019). Mengingat pembuatan sebuah skala dipengaruhi oleh budaya dan cara pandang pembuat skala tersebut. Sehingga saat diadaptasi ke dalam budaya yang berbeda perlu untuk kembali dihitung nilai-nilai yang dihasilkan secara statistik. Selain secara statistik yang tidak kalah pentingnya adalah penggunaan metode kualitatif untuk melihat keterbacaan dan kesesuiaan skala tersebut dengan pandangan hidup masyarakat.

Dalam proses adaptasi skala, scara statistik skala yang diadaptasi harus memenuhi validitas dan reliabelitas. Tetapi dalam pendekatan teori klasik validitas dan relibelitas dapat berubah selama responden yang dilibatkan dalam perhitungan tersebut mengalami penambahan atau pengurangan jumlah, selain itu pendekatan klasik tidak bisa melihat mana aitem yang sulit dipilih responden dan yang mudah untuk dipilih responden.Kelemahan lainnya adalah kontruk yang tidak relevan dengan alat ukur tidak dapat diketahui. Kelemahan yang terjadi pada pengukuran skala secara klasik tersebut dapat diminimalisir dengan menggunakan pendekatan model rasch.Model rasch ini selain mengatasi kekurangan pendekatan klasik di atas juga dapat mengetahui aitem-aitem yang sulit dijawab individu dan responden yang tidak serius dalam mengerjakan skala yang diberikan (Sumintono, 2014). 


\section{METODE}

Penelitian ini menggunakan pendekatan kuantitatif.Jumlah responden penelitian sebanyak 303 mahasiswa, 79 mahasiswa laki-laki dan 224 mahasiswa perempuan yang berasal dari beberapa universitas diantaranya Universitas Ahmad Dahlan Yogyakarta, Universitas Muhamadiyah Enrekang, Sulawesi Barat, Universitas Negeri Manado, Sulawesi Utara, Universitas Mulawarman Kalimantan Timur, Universitas Muhamadiyah Buton, Sulawesi Tenggara dan STKIP Santo Paulus Ruteng Nusa Tenggara Timur, Universitas Tadulako, Sulawesi Tengah, Universitas Haloleo, Sulawesi Tenggara dan STAI Rawa Opa, Sulawesi Tenggara. Pengumpulan data menggunakan google from yang diakses pada bit.ly/skalaconor.

\section{HASIL PENELITIAN DAN PEMBAHASAN}

Uji undimensionalitas merupakan ukuran yang penting untuk mengevaluasi apakah intrumen yang diadaptasi mampu mengukur apa yang seharusnya diukur dalam hal ini adalah resiliensi individu. Berdasarkan perhitungan uji undimensionalitas diketahui bahwa :

Gambar 1 Hasil Uji Unidimensionalitas

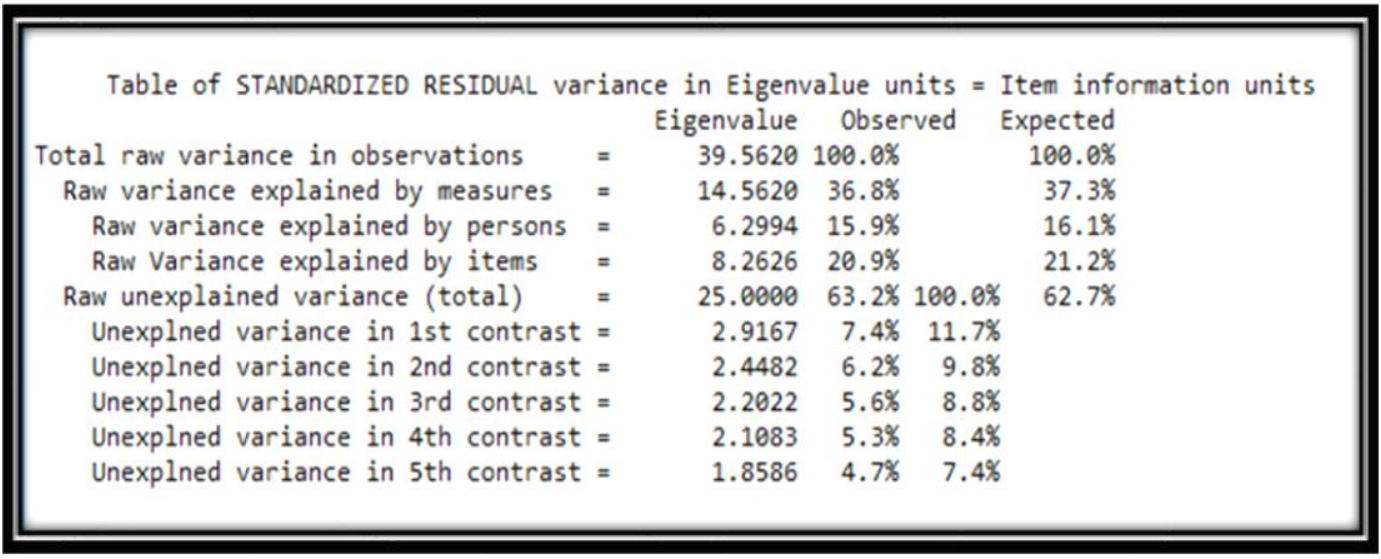

Dari tabel 1, terlihat bahwa hasil pengukuran raw variance data adalah $36,8 \%$. Hal ini menunjukan bahwa persyaratan undimensionalitas minimal $20 \%$ dapat terpenuhi (Sumintono, 2014). Data di atas juga memberikan gambaran bahwa nilai varians bergerak dari 4,7 \% hingga 7,4 \% yang berarti memenuhi persyaratan yang telah ditentukan, karena salah satu syarat agar sebuah intrumen bisa digunakan apabila memiliki nilai varians berada di bawah $15 \%$.Instrumen CD-RISC ini dapat dikatakan dapat mengukur kontruk resiliensi dan mengukur apa yang seharusnya diukur (sehingga tidak ada variant yang diluar dari konstruk yang akan diukur). 
Tabel 2. Item Measure

\begin{tabular}{ccccccc}
\hline \multirow{2}{*}{ Item } & \multirow{2}{*}{ Logit } & \multirow{2}{*}{ SE } & \multicolumn{2}{c}{ Infit } & \multicolumn{2}{c}{ Outfit } \\
\cline { 3 - 7 } & & & MNSQ & ZSTD & MNSQ & ZSTD \\
\hline 1 & .27 & .17 & 1.05 & .36 & 1.10 & .67 \\
\hline 2 & -.25 & .18 & 1.05 & .35 & 1.04 & .29 \\
\hline 3 & -.75 & .19 & 1.47 & 2.57 & 1.35 & 1.93 \\
\hline 4 & .76 & .16 & .86 & -.80 & .88 & -.72 \\
\hline 5 & -.54 & .18 & 1.32 & 1.81 & 1.27 & 1.55 \\
\hline 6 & .00 & .17 & 1.72 & 3.60 & 1.66 & 3.47 \\
\hline 7 & .60 & .16 & 1.00 & .04 & 1.00 & .06 \\
\hline 8 & -.18 & .18 & .70 & -1.96 & .73 & -1.78 \\
\hline 9 & -.61 & .19 & 1.44 & 2.41 & 1.40 & 2.22 \\
\hline 10 & -1.17 & .20 & .83 & -1.07 & .83 & -.91 \\
\hline 11 & .12 & .17 & .89 & -.63 & .89 & -.62 \\
\hline 12 & -.12 & .18 & .90 & -.58 & .90 & -.56 \\
\hline 13 & .63 & .16 & 1.11 & .68 & 1.08 & .54 \\
\hline 14 & .55 & .16 & .93 & -.34 & .89 & -.61 \\
\hline 15 & .89 & .16 & 1.11 & .66 & 1.06 & .41 \\
\hline 16 & -.06 & .17 & .66 & -2.29 & .67 & -2.29 \\
\hline 17 & -.34 & .18 & .90 & -.56 & .86 & -.83 \\
\hline 18 & .86 & .16 & .99 & -.01 & .97 & -.10 \\
\hline 19 & .52 & .17 & 1.04 & .28 & 1.10 & .62 \\
\hline 20 & .63 & .16 & .92 & -.43 & .92 & -48 \\
\hline 21 & -.12 & .18 & .66 & -2.28 & .67 & -2.27 \\
\hline 22 & .41 & .17 & .74 & -1.64 & .76 & -1.52 \\
\hline 23 & .41 & .17 & .85 & -.87 & .90 & -.57 \\
\hline 24 & -.61 & .19 & 1.20 & 1.20 & 1.08 & .54 \\
\hline 25 & -1.86 & .23 & .95 & -.21 & .86 & -.55 \\
\hline & & & & & & \\
\hline
\end{tabular}

Pengujian terhadap aitem-aitem skala menunjukan bahwa berdasarkan nilai logit maka aitem nomer 15 merupakan aitem yang sulit untuk dijawab karena mendapatkan nilai logit sebesar 0.89 adapun bunyi aitem adalah "lebih suka memimpin dalam pemecahan masalah". Sedangkan aitem yang mudah dijawab adalah aitem nomer 25 dengan nilai logit -1.86 dengan bunyi pernyataan “menghargai prestasi sendiri”.Selanjutnya aitem fit dalam pemodelan rasch digunakan unntuk mengetahui aitem-aitem mana yang sesuai dan yang tidak sesuai.

Untuk memeriksa item fit dan misfit bisa digunakan nilai Infit MNSQ dari setiap aitem (Sumintono, 2014; Sumintono \& Widhiarso, 2014).Kriteria dalam menentukan aitem yang tidak sesuai adalah, a) nilai MNSQ yang diterima adalah $0,5<\mathrm{MNSQ}<1$,5.dan nilai ZSTD yang diterima 2.0<ZSTD<+2.0 (Sumintono \& Widhiarso, 2014). Bila merujuk kepada kriteria lainnya dimana nilai outfit dan infit lebih dari 1.4 logit, maka aitem tersebut dikatakan membingungkan (Linacre, 2007). 
Dari tabel di atas diketahui nilai aitem nomer 6 dan nomer 9 melebihi standar yang ditentukan. Aitem pernyataan nomer 6 adalah "melihat sesuatu dari sisi humoris atau menyenangkan" dan aitem pernyataan nomer 9 adalah "sesuatu hal dapat terjadi karena sesuatu alasan".

Tabel 3. Nilai Reliabilitas

\begin{tabular}{|l|c|c|c|c|}
\hline & Person & Aaitem & Cronbach Alfa & Measure \\
\hline Reliabelitas & .88 & .92 & .90 & \\
\hline Sparation & 2.68 & 3.42 & & \\
\hline Measure & \multicolumn{4}{|l}{} \\
\hline
\end{tabular}

Berdasarkan nilai reliabilitas diketahui bahwa nilai reliabelitas person 0.88 berada pada kategori bagus, nilai reliabelitas aitem sebesar 0.92 berada pada kategori bagus sekali dan nilai Alfa Cronbach sebesar 0.90 dalam kategori bagus sekali(Sumintono \& Widhiarso, 2014).Nilai aitem sparation menunjukan tingkat pengukuran dengan nilai 3,42 yang tergolong sangat baik. Nilai sparation person adalah 2,68 yang berada pada katagori minimum yang disyaratkan, makin besar nilai sparation ini maka kualitas intrumen dalam hal keseluruhan responden dan aitem makin bagus karena mampu mengidentifikasi kelompok aitem dan kelompok responden (Sumintono \& Widhiarso, 2014). Nilai measure 1.63 menunjukan bahwa nilai rata rata yang diperoleh responden dalam intrumen skala yang diadaptasi.Nilai rata rata yang lebih dari 0,0 menunjukan kecenderungan responden yang lebih banyak memilih sesuai pada statemen di berbagai aitem (Sumintono \& Widhiarso, 2014)

Tabel 1.4 Skala Peringkat

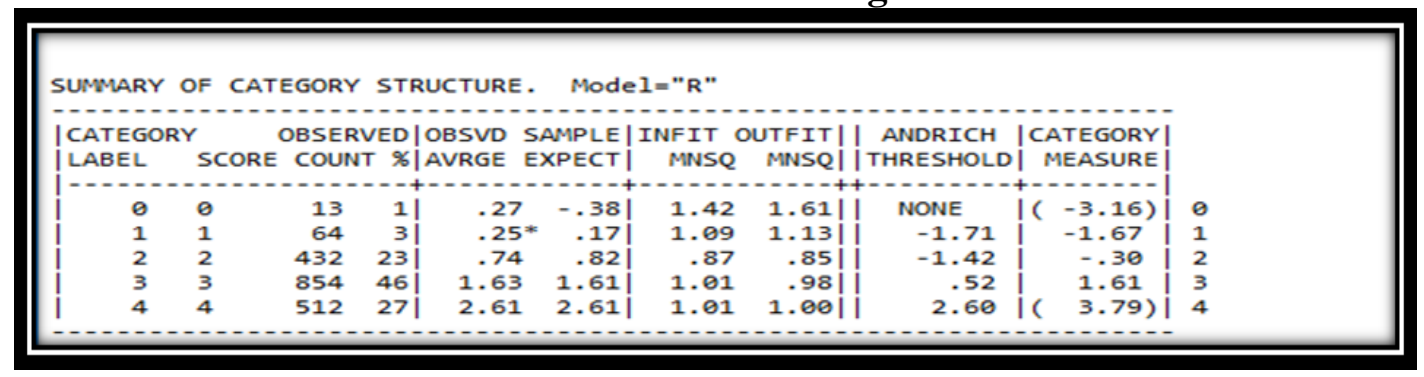

Pada tabel di atas terlihat bahwa rata observasi dimulai dari nilai 0.27 untuk pilihan skor 0 , kemudian pilihan dengan skor 1 sebesar 0,25 dan meningkat ke nilai 2.61 pada skor 4 . Terlihat dari data di atas pilihan skor 0 ke skor 1 tidak ada peningkatan nilai, namun mengalami penurunan, ini menunjukan responden tidak bisa memastikan antara memilih skor 0 dan skor 1 (Sumintono \& Widhiarso, 2014).

\section{SIMPULAN}

Hasil analisis menunjukan bahwa skala adaptasi CD-RISC scara perhitungan model rasch dapat digunakan. Nilai perhitungan aitem reliabelitas dan person reliabelitas menunjukan nilai yang baik dengan nilai 0.92 dan 0.88.Nilai yang dihasilkan ini tidak tergantung dengan jumlah responden 
dan karakteristik responden yang selama ini digunakan untuk menganalisa validitas dan reliabelitas skala berdasarkan perhitungan klasik.Hasil penelitian juga menunjukan bahwa ada aitem aitem yang membingungkan responden yaitu aitem nomer 6 dan nomer 9. Sedangkan aitem yang sulit dijawab responden adalah aitem nomer 15.Aitem yang paling mudah dipilih oleh responden adalah aitem nomer 25 .

\section{DAFTAR RUJUKAN}

Amir, S., \& Kant, V. (2018). Sociotechnical resilience: A preliminary concept. Risk Analysis, 38(1), $8-16$.

Apneseth, K., Wahl, A. M., \& Hollnagel, E. (2018). Measuring Resilience in Integrated Planning. In Oil and Gas, Technology and Humans (pp. 145-162). CRC Press.

Becvar, D. S. (2012). Handbook of family resilience. Springer Science \& Business Media.

Cohen, E., Eshel, Y., Kimhi, S., \& Kurman, J. (2019). Individual resilience: A major protective factor in peer bullying and victimization of elementary school children in Israel. Journal of Interpersonal Violence, 0886260519863192.

Ensor, J., Forrester, J., \& Matin, N. (2018). Bringing rights into resilience: Revealing complexities of climate risks and social conflict. Disasters, 42, S287-S305.

Feder, A., Torres, S. F., Southwick, S. M., \& Charney, D. S. (2019). The Biology of Human Resilience: Opportunities for Enhancing Resilience across the Lifespan. Biological Psychiatry.

García-León, M. Á., Caparrós-González, R. A., Romero-González, B., González-Perez, R., \& Peralta-Ramírez, I. (2019). Resilience as a protective factor in pregnancy and puerperium: Its relationship with the psychological state, and with Hair Cortisol Concentrations. Midwifery, 75, $138-145$.

Gras Pérez, M. E., Font-Mayolas, S., Baltasar Bagué, A., Patiño Masó, J., Sullman, M. J., \& Planes Pedra, M. (2019). The Connor-Davidson resilience scale (CD-RISC) amongst young spanish adults $=$ La escala de resiliencia de Connor-Davidson en adultos españoles jóvenes. Clínica y Salud: Investigación Empírica En Psicologia, 2019, Vol. 30, Num. 2, p. 73-79.

Guzmán, C. G., Martín, M. B. G., Falcón, J. S., \& Sierra, M. A. (2019). Psychometric Properties of the Connor-Davidson Resilience Scale (CD-RISC) on Vulnerable Colombian Adolescents. International Journal of Psychology and Psychological Therapy, 19(3), 277-289.

Hoorelbeke, K., Van den Bergh, N., Wichers, M., \& Koster, E. H. (2019). Between vulnerability and resilience: A network analysis of fluctuations in cognitive risk and protective factors following remission from depression. Behaviour Research and Therapy, 116, 1-9. 
Kuiper, H., van Leeuwen, C. C., Stolwijk-Swüste, J. M., \& Post, M. W. (2019). Measuring resilience with the Connor-Davidson resilience scale (CD-RISC): Which version to choose? Spinal Cord, $57(5), 360-366$.

Kwan, Y. H., Ng, A., Lim, K. K., Fong, W., Phang, J. K., Chew, E. H., Lui, N. L., Tan, C. S., Thumboo, J., \& Østbye, T. (2019). Validity and reliability of the ten-aitem Connor-Davidson Resilience Scale (CD-RISC10) instrument in patients with axial spondyloarthritis (axSpA) in Singapore. Rheumatology International, 39(1), 105-110.

Linacre, J. M. (2007). Realiability and Separations. A Users Guide to Winsteps/Ministep RaschModel Computer Programs Chicago: Winsteps. Com.

Manyena, B., Machingura, F., \& O'Keefe, P. (2019). Disaster Resilience Integrated Framework for Transformation (DRIFT): A new approach to theorising and operationalising resilience. World Development, 123, 104587.

Papini, N., Kang, M., Ryu, S., Griese, E., Wingert, T., \& Herrmann, S. (2020). Rasch calibration of the 25-aitem Connor-Davidson Resilience Scale. Journal of Health Psychology, 1359105320904769.

Resnick, B. (2018). The relationship between resilience and motivation. In Resilience in Aging (pp. 221-244). Springer.

Sciences, S., Le Menestrel, S., Kizer, K. W., National Academies of Sciences, \& Medicine. (2019). Family Well-Being, Readiness, and Resilience. In Strengthening the Military Family Readiness System for a Changing American Society. National Academies Press (US).

Southwick, S. M., Sippel, L., Krystal, J., Charney, D., Mayes, L., \& Pietrzak, R. (2016). Why are some individuals more resilient than others: The role of social support. World Psychiatry, 15(1), 77.

Stapelfeldt, C. M., Momsen, A.-M. H., Lund, T., Grønborg, T. K., Hogg-Johnson, S., Jensen, C., Skakon, J., \& Labriola, M. (2019). Cross-Cultural Adaptation, Reliability and Validity of the Danish Version of the Readiness for Return to Work Instrument. Journal of Occupational Rehabilitation, 29(2), 325-335.

Sumintono, B. (2014). Model Rasch untuk penelitian sosial kuantitatif.eprint.um.edu.my

Sumintono, B., \& Widhiarso, W. (2014). Aplikasi model Rasch untuk penelitian ilmu-ilmu sosial (edisi revisi). Trim Komunikata Publishing House. 
Turk, E. W., \& Wolfe, Z. M. (2019). Principal's Perceived Relationship between Emotional Intelligence, Resilience, and Resonant Leadership throughout Their Career. International Journal of Educational Leadership Preparation, 14(1), 147-169.

Wagnild, G. (2009). A review of the Resilience Scale. Journal of Nursing Measurement, 17(2), 105113.

Woodgate, R. L. (1999). Conceptual understanding of resilience in the adolescent with cancer: Part I. Journal of Pediatric Oncology Nursing, 16(1), 35-43.

Zhang, J., Guo, F., Chen, Z. Y., He, H. W., Long, Y., \& Li, Q. (2020). Relationship between social support, resilience, self-esteem and post-traumatic stress disorder in intensive care unit nurses. Zhonghua Yi Xue Za Zhi, 100(1), 32. 